\title{
Clinical Manifestations of the Opiate Withdrawal Syndrome
}

\author{
Faniya Shigakova \\ Tashkent Medical Academy, Tashkent, Uzbekistan
}

\begin{abstract}
Currently, substance abuse is one of the most serious problems facing our society. The aim of this study was to investigate the clinical manifestations of the opiate withdrawal syndrome (OWS). The study included 112 patients (57 women and 55 men) aged from 18 to 64 years with opium addiction according to the DSM-IV. To study the clinical manifestation of OWS, the special 25-score scale with four sections to assess severity of sleep disorders, pain syndrome, autonomic disorders, and affective symptoms was used. Given the diversity of the OWS symptoms, attention was focused on three clinical variants, affective, algic and mixed. The OWS affective variant was registered more frequently in women, while the mixed type of OWS was more typical of men. (Int J Biomed. 2015;5(3):151-154.)
\end{abstract}

Key words: Opiate withdrawal syndrome (OWS); OWS 25-score scale.

\section{Introduction}

Currently, substance abuse is one of the most serious problems facing our society. A wide diversity of clinical signs and symptoms of substance abuse contributes to the development of novel diagnostic and therapeutic strategies [1, $2,3]$. Full-value treatment of opioid addicts depends on rapid and successful coping with withdrawal disorders. Clinical picture of the opiate withdrawal syndrome (OWS) involves a constellation of symptoms. Typically OWS presents concurrently as several of the following signs: algesic, autonomic, emotional, sleep, psychopathic, hypochondriac, and other disorders $[4,5]$. Peculiar bothersome sensations localizing in muscles, joints, skin, and other parts of body are the most torturous symptoms. These sensations are close to the painful feelings, but at the same time they differ from them, resembling senestopathies [6]. Accompanied by specific autonomic disorders, such as chill, sweating, rhinorrhea, dry mouth, and nausea, these sensations cause disproportionately potent emotional response with prevailing depressivehypochondriac and dysphoric symptoms $[7,8]$.

T. Galaktionova [9] studied a syndrome-based structure of the acute conditions in opiate addicts and proposed a classification, which distinguishes the algic (pain), mixed, and affective forms of OWS. This classification, which is very

*Corresponding author: Faniya Shigakova. Tashkent Medical Academy,Tashkent, Uzbekistan.E-mail:pilar.buranova@mail.ru handy for physicians, directly associates the algic (pain) and mixed forms with the pain and autonomic syndromes; while the emotional lability, irritability, low mood, anxiety and dysphoria can be seen in the clinical structure of the affective syndrome of OWS. The identification of the main symptoms and their removal determines the successful treatment strategy for OWS. Successful treatment of OWS is the subject of great therapeutic efforts.

The aim of this study was to investigate the clinical manifestations of the opiate withdrawal syndrome.

\section{Materials and methods}

The study included 112 patients ( 57 women and 55 men) aged from 18 to 64 years with opium addiction according to the Diagnostic and Statistical Manual of Mental Disorders, 4th Edition (DSM-IV), 2000) [10]. The study included patients who voluntarily sought treatment for opioid dependence and was performed at the Republican addiction treatment center (Tashkent, the Republic of Uzbekistan) during 2010 to 2014. All patients underwent detoxification (no more than 20 days) and had to be off opiates for at least 7 days before the study.

The mean age of women was $32.9 \pm 8.6$ years (Me 32 years; IQR 27.0-36.0), and of men it was $35.7 \pm 5.8$ years (Me 36 years; IQR 31.5-39.0). The exclusion criteria were as follows: mental derangements in addition to drug addiction, a lack of follow-up information, mixing heroin with other drugs, and heroin use as a substitution for other psychoactive substances. 
The study was approved by the independent ethic committee and conducted in accordance with good clinical practice guidelines and the World Medical Association Declaration of Helsinki. Written informed consent was obtained from each patient.

The mean age of substance use onset at the moment of primary examination was $24.6 \pm 6.7$ years (Me 23.0 years; IQR 19.0-29.0); the duration of heroin abuse ranged from 2 months to 23 years $(9.5 \pm 5.1$ years; $M e 9.5$ years; IQR 5.0-13.0). The vast majority of the patients have used heroin for less than 12 years $(67.9 \%$ vs. $32.1 \%$; OR=4.46; 95\% CI:2.54-7.81; $P=0.000)$. The majority of patients $(82.1 \%)$ used heroin intravenously.

To study the clinical manifestation of OWS, we have used a special 20-score scale developed by M. Treschinskaya and V. Khrykin [11]. This scale includes three sections to assess the severity of sleep disorders (including agrypnia), pain syndrome, and autonomic manifestations. In our modification, this scale has been supplemented by new section to assess the affective variant of OWS. Thus, the final scale consisted of 25 items designed to assess the severity of OWS. A five-score subscale is used to assess severity of sleep disorders (Section 1) ranging from 1 score for sleep less than one hour a night to 5 scores for a duration of sleep more than 7 or 8 hours. Similar maximum generalized 5-score subscale is intended for assessment of pain syndrome severity (Section 2). Autonomic disorders (Section 3 ) are assessed by three subsections. Thus, a 4-score subscale is used to assess intestine dysfunction severity, a 3-score subscale serves to monitor changes in salivation, and a 3-score subscale is intended for assessment of rhinorrhea. The last 5-score subscale serves to assess the affective manifestation (Section 4). This questionnaire for assessment of the OWS severity (Table 1) is filled in by a doctor in charge for each patient.

Table 1.

Questionnaire for assessment of the OWS severity

\begin{tabular}{|c|c|c|c|}
\hline $\begin{array}{c}\text { Clinical parameters of } \\
\text { OWS }\end{array}$ & Score & $\begin{array}{c}\text { Clinical parameters of } \\
\text { AWS }\end{array}$ & Score \\
\hline $\begin{array}{l}\text { 1. Sleep and sleep disorders } \\
\text { Sleep duration }\end{array}$ & & $\begin{array}{l}\text { Loose stool } 4-5 \text { times a } \\
\text { day }\end{array}$ & 2 \\
\hline $7-8$ and more hours a day & 5 & $\begin{array}{l}\text { Loose stool more than } 5 \\
\text { times a day }\end{array}$ & 1 \\
\hline Under 7 hours & 4 & B. Salivation & \\
\hline Under 5 hours & 3 & Normal & 3 \\
\hline Under 3 hours & 2 & Moderately high & 2 \\
\hline Less than 1 hour a day & 1 & Acutely high & 1 \\
\hline 2. Pain syndrome & & C. Rhinorrhea & \\
\hline No manifestations & 5 & No manifestations & 3 \\
\hline Mild & 4 & Moderate & 2 \\
\hline Moderate & 3 & Severe & 1 \\
\hline Severe & 2 & 4. Affective syndrome & \\
\hline Severest & 1 & Emotional lability & 5 \\
\hline 3. Autonomic disorders & & Irritability & 4 \\
\hline A. Intestine dysfunctions & & Feeling low, anxiety & 3 \\
\hline $\begin{array}{l}\text { No diarrhea (solid stool } \\
1-2 \text { times a day) }\end{array}$ & 4 & Dysphoria & 2 \\
\hline $\begin{array}{l}\text { Soft or loose stool 2-3 } \\
\text { times a day }\end{array}$ & 3 & Psychomotor excitation & 1 \\
\hline \multicolumn{4}{|l|}{ Total score } \\
\hline
\end{tabular}

Affective syndrome with concurrent emotional lability, irritability, low mood and anxiety scores 5, 4 and 3 , respectively; the one with dysphoria or psychomotor excitation scores 2 . To assess severity of affective syndrome only leading symptom is set aside. The total sum of scores is used to interpret the parameters of OWS scale. Thus, the total sum of scores ranging from 22 to 25 indicates a mild OWS and a patient's compensated condition, one ranging from 16 to 21 reflects a moderate compensated OWS. Range of 13-15 scores indicates a marked compensated AWS, the one of 12-17 scores reflects a compensated highly marked OWS; the total sum of scores less than 7 is the evidence for the decompensated OWS. On the basis of the scores we can determine the OWS variant as affective, algic or the mixed one, which takes an intermediate position between affective and algic one.

All data were processed by means of STATISTICA 6 and BIOSTAT software packet. Quantitative parameters are presented as $\mathrm{M} \pm \mathrm{SD}$, Median $(\mathrm{Me})$, and 25th and 75th percentiles (IQR, Inter Quartile Range). Odds ratio (OR) with $95 \%$ confidence interval (CI) was calculated for each factor. Statistical significance of differences between parameters in the sample was assessed by means of non-parametric $\chi 2$ test (Pearson's criterion). Minimum significance was set at $P \leq 0.05$.

\section{Results}

Given the diversity of the OWS symptoms, we focused on three following clinical variants.

OWS affective variant was registered in $42(37.5 \%)$ patients, $29(69.0 \%)$ women and $13(23.6 \%)$ men among them. In this group of patients an algic or pain component was found mild scoring $3.4 \pm 0.7$; seem to be minor for the patients autonomic symptoms scoring $7.3 \pm 1.3$ were found insignificant. More than half of patients with the OWS affective variant $(57.1 \%)$ actively and sometimes importunately complained of embarrassment, anxious expectation, and foreboding of evil. Affective component was the marked one (scoring 2.5 \pm 0.7 ) manifesting in anxiety (in 57.1\%) and dysphoria (in $31.0 \%$ ); psycho-motor excitation was registered more rarely (in 9.5\%) (Table 2). Sleep disorders scored $3.1 \pm 0.8$. This variant was registered significantly more frequently among women than among men $(\mathrm{OR}=4.98 ; 95 \% \mathrm{CI}$ : 1.97-12.6; $P=0.001)$.

AWS algic variant was observed in $35(31.2 \%)$ patients, $16(45.7 \%)$ women and $19(54.3 \%)$ men among them. These patients within post-withdrawal period complained of dragging and twisting pain in the lumbar region, knee joints, and gastrocnemius muscles. The OWS algic component scored 2.6 \pm 0.7 . In this group most patients (71.4\%) described unusual, peculiar and bothersome sensations characterizing them as "tearing flesh off the bones", "twisting of joints", "itching bones"; some mentioned a flu-like twisting body pain. The sensations above, particularly, those of high intensity were accompanied by a patient's fussiness and restlessness; the patient needed to change position of his/her body once and again. At the same time, patients complained of a chill followed by a fever; salivation, lacrimation, and sneezing took place. In this group of patients, the autonomic component scored $6.6 \pm 1.4$, affective one was mild scoring $3.4 \pm 0.7$. Sleep 
disorders were also typical for the patients with this OWS variant, scoring 3.0 \pm 0.9 . The frequency of this AWS variant among women and men was similar ( $\mathrm{OR}=0.71 ; 95 \%$ CI: 0.28 $1.82 ; P=0.63$ )

AWS mixed variant taking an intermediate position between the OWS affective and algic variants was found in $35(31.2 \%)$ patients, $12(34.3 \%)$ women and $23(65.7 \%)$ men among them. This group of patients comprised those with algic, autonomic and affective disorders scoring 3.2 \pm 0.7 , $7.4 \pm 1.3$ and $3.01 \pm 0.7$, respectively; that is, presentation of the disorders in the OWS clinical picture was almost equal. These patients complained of unwellness, embarrassment and bothersome sensations poorly localized in the body; these numerous complaints were undifferentiated. Requiring greater attention from others, the patients were cranky and bad tempered. Sleep disorders in this group of patients were less severe than in those with algic variant, and scored 3.4 \pm 0.7 . This variant of OWS was registered in men more frequently than in women $(\mathrm{OR}=3.67 ; 95 \% \mathrm{CI}: 1.36-9.89 ; P=0.02)$.

Table 2.

Parameters of the OWS severity

\begin{tabular}{|c|c|c|c|c|c|c|}
\hline \multirow{3}{*}{ Clinical parameters of OWS } & \multicolumn{6}{|c|}{ OWS variants } \\
\hline & \multicolumn{2}{|c|}{$\begin{array}{c}\text { affective } \\
\mathrm{n}=42\end{array}$} & \multicolumn{2}{|c|}{$\underset{n=35}{\operatorname{algic}}$} & \multicolumn{2}{|c|}{$\underset{\mathrm{n}=35}{\operatorname{mixed}}$} \\
\hline & $\mathrm{n}$ & $\%$ & $\mathrm{n}$ & $\%$ & $\mathrm{n}$ & $\%$ \\
\hline \multicolumn{7}{|c|}{ 1. Sleep and sleep disorders. Sleep duration } \\
\hline $7-8$ or more hours a day & - & - & 1 & 2.9 & - & - \\
\hline Under 7 hours & 13 & 31.0 & 11 & 31.4 & 19 & 54.3 \\
\hline Under 5 hours & 22 & 52.4 & 11 & 31.4 & 13 & 37.1 \\
\hline Under 3 hours & 7 & 16.7 & 12 & 34.3 & 3 & 8.6 \\
\hline Less than 1 hour a day & - & - & - & - & - & - \\
\hline \multicolumn{7}{|l|}{ 2. Pain syndrome } \\
\hline No manifestations & - & - & - & - & - & - \\
\hline Mild & 23 & 54.8 & 3 & 8.6 & 10 & 28.6 \\
\hline Moderate & 15 & 35.7 & 17 & 48.6 & 22 & 62.9 \\
\hline Severe & 4 & 9.5 & 14 & 40.0 & 2 & 5.7 \\
\hline Severest & - & - & 1 & 2.9 & 1 & 2.9 \\
\hline \multicolumn{7}{|l|}{ 3. Autonomic disorders } \\
\hline \multicolumn{7}{|l|}{ A. Intestine dysfunctions } \\
\hline $\begin{array}{l}\text { No diarrhea (solid stool 1-2 } \\
\text { times a day) }\end{array}$ & 3 & 7.1 & 3 & 8.6 & 4 & 11.4 \\
\hline Soft or loose stool 2-3 a day & 23 & 54.8 & 13 & 37.1 & 20 & 57.1 \\
\hline Loose stool 4-5 times a day & 16 & 38.1 & 15 & 42.9 & 10 & 28.6 \\
\hline $\begin{array}{l}\text { Loose stool more than } 5 \\
\text { times a day }\end{array}$ & - & - & 4 & 11.4 & 1 & 2.9 \\
\hline \multicolumn{7}{|l|}{\begin{tabular}{|l|} 
B. Salivation \\
\end{tabular}} \\
\hline Normal & 13 & 31.0 & 3 & 8.6 & 9 & 25.7 \\
\hline Moderately high & 27 & 64.3 & 30 & 85.7 & 25 & 71.4 \\
\hline Acutely high & 2 & 4.8 & 2 & 5.7 & 1 & 2.9 \\
\hline \multicolumn{7}{|l|}{ C. Rhinorrhea } \\
\hline No manifestations & 14 & 33.3 & 9 & 25.7 & 13 & 37.1 \\
\hline Moderate & 28 & 66.7 & 23 & 65.7 & 22 & 62.9 \\
\hline Severe & - & - & 3 & 8.6 & - & - \\
\hline \multicolumn{7}{|l|}{ 4. Affective syndrome } \\
\hline Emotional lability & - & - & 1 & 2.9 & - & - \\
\hline Irritability & - & - & 15 & 42.9 & 10 & 28.6 \\
\hline Feeling low, anxiety & 25 & 59.5 & 18 & 51.4 & 22 & 62.9 \\
\hline Dysphoria & 13 & 31.0 & - & - & 1 & 2.9 \\
\hline Psychomotor excitation & 4 & 9.5 & 1 & 2.9 & 2 & 5.7 \\
\hline
\end{tabular}

\section{Discussion}

The findings from our study confirm some authors' opinion concerning presence of some variants in OWS, to name affective, algic and mixed $[9,12,13]$. In our study sleep disorders of similar intensity could be seen in all three variants, autonomic symptoms were more pronounced in algic one. K.Mosikyan [12] concludes that clinical parameters underlying the formation of opium addiction as well as presence of concurrent psychic pathology determine formation of clinical variant of opium withdrawal syndrome. Affective variant of opium withdrawal syndrome is typical of persons with unstable type of premorbid personality, moderately progressive course of addiction and short duration of substance abuse.

Since OWS affective variant in our study was registered more frequently among women than among men and the mixed one was typical of male opium addicts, it is possible to speak of gender peculiarities in the clinical picture of OWS. Opium abuse duration was found not to influence OWS variant. Previously, gender peculiarities were found in the type of opium abuse course [14].

\section{Conclusions}

Clinical picture of acute withdrawal syndrome has been proved to be diverse. In our study we observed some OWS clinical variants with peculiarities significant for diagnosis and treatment strategy. It is of importance that OWS affective variant was registered more frequently in women, while the mixed type of acute withdrawal syndrome was more typical of men. We believe that these features taken into account would help improve the effectiveness of opioid addiction treatment.

\section{References}

1. Anokhina IP, Ivanets NN, Shamakina I.Yu. Up-to-date problems in genetics of psychoactive substances dependence. Addiction Medicine. 2004; 6:71-77. [in Russian].

2. Vinnikova MA. Post-withdrawal conditions upon heroin addiction (clinical picture and treatment). Abstract of $\mathrm{PhD}$ Thesis. Moscow; 2004. [in Russian].

3. Rokhlina ML, Mokhnachoyv SO. Peculiarities of formation and clinical picture of heroin addiction with gender differences taken into account. Moscow: Medicine; 2003. [in Russian].

4. Gofman AG. Clinical addiction medicine. Moscow: Miklosh; 2003. [in Russian].

5. Sivolap YuP, Savchenkov VA. Opioid abuse and dependence. Moscow: Medicine; 2005. [in Russian].

6. Pyatnitskaya IN. Addictions. Moscow: Medicine; 1994. [in Russian].

7. Desmond DP, Maddux JF. Deaths among heroin users in and out of methadone treatment. J Mainten Addict. 2000; 4(1):45-61.

8. Hopfer CJ, Khuri E, Crowley T, Hooks A. Adolescent heroin use: a review of the descriptive and treatment literature. J Subst Abuse Treat. 2002; 23(3):231-37.

9. Galaktionova TE. Clinical variants of heroin addiction in aspect of differentiated therapy. Abstract of $\mathrm{PhD}$ Thesis. Moscow; 2009 [in Russian].

10. American Psychiatric Association. Diagnostic and 
Statistical Manual of Mental Disorders, 4th Edition, Text Revision (DSM-IV-TR). Washington, DC, 2000.

11. Treschinskaya MA, Khrykin VN. OWS1 and OWS2 scales for clinical interpretation of course and severity of opium withdrawal syndrome. Emergencies Medicine. 2010; 4(29):34-37. [in Russian].

12. Mosikyan KL. Opium withdrawal syndrome. Abstract of
PhD Thesis. Moscow; 2006. [in Russian].

13. Shevchenko NN. Clinical picture and therapy of opium (heroin) addiction in high north nonresidents. Abstract of $\mathrm{PhD}$ Thesis. Moscow; 2007. [in Russian].

14. Shigakova F.A. Clinical aspects of highly progressive opium addiction in women. Addiction Medicine Problems. 2013;5:11-17 [in Russian]. 